\title{
POVOADO BICA: PROCESSOS DE ORGANIZAÇÃO PELO RECONHECIMENTO E TITULAÇÃO DA TERRA EM ALDEIA VELHA - PIRAPEMAS (MA)
}

\author{
Tânia Nazarena de Oliveira Miranda ${ }^{1}$
}

\begin{abstract}
RESUMO
Este trabalho foca no processo de recomposição territorial construída pelas comunidades quilombolas do Povoado Aldeia Velha em Pirapemas, no estado do Maranhão. De forma particular apresentamos o povoado Bica, em consideração ao processo político desencadeado pelas lideranças e instituições históricas do Maranhão, à frente da associação pelo reconhecimento estatal do direito das comunidades afrodescendentes e, assim instituir, os procedimentos para identificação, reconhecimento, delimitação, demarcação e titulação das terras (RTID), ocupadas por remanescentes das comunidades dos Quilombos de que trata o Art.68 do Ato das Disposições Constitucionais Transitórias da Constituição Federal de 1988 e do Decreto n ${ }^{\circ} 4.887$, de 20 de novembro de 2003. Com a aprovação do convênio entre o INCRA e uma empresa terceirizada, deu-se início a primeira peça, o Relatório Antropológico. Para a composição do relatório, realizou-se o levantamento bibliográfico de conceitos concernentes à etnicidade, ancestralidade, quilombolas e uso comum da terra; estes contribuíram para a caracterização da trajetória histórica da comunidade estudada e suas relações territoriais. A primeira peça foi aprovada tecnicamente pelo INCRA (MA), por meio da certificação de sua ancestralidade, identidade e saberes. Concluímos que o processo de resistência das comunidades quilombolas na Aldeia Velha, foi importante para o início de titulação das terras, no entanto, haverá muitos outros processos para garantir o título definitivo.
\end{abstract}

Palavras-chave: Organização política. Etnicidade. Território.

\section{BICA VILLAGE: ORGANIZATION PROCESSES FOR THE RECOGNITION AND TITLING OF LAND IN ALDEIA VELHA - PIRAPEMAS (MA)}

\begin{abstract}
This work focuses on the process of territorial reconstruction built by the quilombola communities in the Aldeia Velha Village in Pirapemas, in the state of Maranhão. In a particular way, we present the Bica village, in consideration of the political process triggered by the leaders and historical institutions of Maranhão, ahead of the association for the state recognition of the rights of Afro-descendant communities and, thus, instituting the procedures for identification, recognition, delimitation, demarcation and titling of lands (RTID), occupied by remnants of Quilombo communities referred to in Art.68 of the Transitory Constitutional Provisions Act of the Federal Constitution of 1988 and Decree $\mathrm{n}^{\circ} 4.887$, of November $20^{\text {th }}, 2003$. With the approval of the agreement between INCRA and an outsourced company, the first piece, the Anthropological Report, started. For the composition of the report, a bibliographic survey of concepts concerning ethnicity, ancestry, quilombolas and common land use was carried out; these contributed to the characterization of the historical trajectory of the studied community and its territorial relations. The first piece was technically approved by INCRA (MA), by certifying its ancestry, identity and knowledge. We concluded that the resistance process of the quilombola communities in Aldeia Velha was important for the beginning of land titling, however, there will be many other processes to guarantee the definitive title.
\end{abstract}

Keywords: Political organization. Ethnicity. Territory.

1 Doutorado em Sociologia e Antropologia - Universidade Federal do Pará- UFPA. E-mail: taniamiranda18@yahoo.com.br. 


\section{Résumé}

Ce travail porte sur le processus de recomposition territoriale construit par les communautés quilombolas de Povoado Aldeia Velha à Pirapemas, dans l'État du Maranhão. De manière particulière, nous présentons le village de Bica, en considération du processus politique déclenché par les dirigeants et les institutions historiques du Maranhão, à la tête de l'association pour la reconnaissance par l'État des droits des communautés afro-descendantes et, ainsi, instituant les procédures d'identification, de reconnaissance, de délimitation, de démarcation et d'attribution de titres fonciers (RTID), occupés par les restes des communautés Quilombo visées à l'article 68 de la loi sur les dispositions constitutionnelles transitoires de la Constitution fédérale de 1988 et le décret $n^{\circ} 4887$ du 20 novembre , 2003. Avec l'approbation de l'accord entre l'INCRA et une société tierce, la première pièce a été lancée, le Rapport Anthropologique. Pour la composition du rapport, une étude bibliographique des concepts concernant l'ethnicité, l'ascendance, les quilombolas et l'utilisation commune des terres a été réalisée, ce qui a contribué à la caractérisation de la trajectoire historique de la communauté étudiée et de ses relations territoriales. La première pièce a été techniquement approuvée par l'INCRA (MA), grâce à la certification de son ascendance, de son identité et de ses connaissances. Nous avons conclu que le processus de résistance des communautés quilombolas à Aldeia Velha était important pour le début de l'attribution de titres fonciers, cependant, il y aura de nombreux autres processus pour garantir le titre définitif.

Mots-clés: Organisation politique. Ethnicité. Territoire.

Data de submissão: 28.07 .2021

Data de aprovação: 27.09 .2021

\section{INTRODUÇÃO}

As Comunidades Quilombolas em contexto nacional, ao identificar-se como comunidades negras ganham o estatuto de unidades culturais e sociais, por partilharem uma origem e uma cosmologia comuns, uma ancestralidade, por apresentar grandes índices de endogamia e até mesmo um dialeto particular, assim, para o polo do 'isolamento', da 'alteridade', do 'exotismo' do universo de referências 'autônomo e original'" (ARRUTI, 2002, p. 11). Tanto as comunidades negras rurais como as comunidades indígenas, passaram por processos de retomada de tradições, a partir de uma identidade genérica de caboclos já assimilados, sem uma língua distinta, cristianizados, muitas vezes integrados aos mercados local e nacional como força de trabalho móvel.

O pensamento social brasileiro, ao olhar grupos sociais considerados irrelevantes, atuou no campo de estudos étnicos, com passagens nos anos de 1930, se acalorando a partir dos anos de 1960 a 1990, com abordagens semânticas e históricas, até culminar com o Art. 68 , que reconhece as 'comunidades remanescentes de quilombos, mesmo que transitória e sem definição jurídica institucional.

O quilombo, enquanto categoria histórica, detém um significado relevante, localizado no tempo e, é objeto de uma reinterpretação jurídica, quando empregado para legitimar reivindicações pelo território dos ancestrais por parte dos denominados remanescentes de quilombos. O termo reatualizado, ocorre a partir dos anos de 1980, como resultado das mobilizações de grupos rurais, do movimento negro e de entidades de apoio às lutas pelo reconhecimento jurídico das terras de antiga ocupação. (ACEVEDO; CASTRO, 1998, p. 24).

A emergência de grupos sociais e a organização das comunidades quilombolas, está vinculada a lutas, para as conquistas de direitos sociais na área rural e/ou do campo, que criam lutas específicas e contribuem para o estabelecimento e promulgação de leis, também particulares. Ao falar especificamente da Amazônia, Almeida (2009) sinaliza que as ações políticas movidas no campo, são centradas na reivindicação da permanência na terra. Trata-se de seguimentos diferenciados pela proposta de demarcação de terras de antiga ocupação; sua 
origem, formação e situações distintas permitem estabelecer diversas experiências e processos que ressignificam a terra para cada comunidade. É no meio de situações de tensões e de enfrentamento, que os processos de formação de identidade mobilizam e, assim, alforriam fragmentos de histórias comum e da memória social.

Ao buscar os fragmentos dessa história comum e conjugar com memórias de lideranças e "historiadores populares e comunitários", recupera-se processos que levam ao reconhecimento de sua ancestralidade de ocupação, uso coletivo da terra, identidade e etnicidade. Tais narrativas, buscadas na história do lugar, do território, não apenas de um tempo passado, mas do tempo presente, vivido pelos descendentes no território, que vão se imiscuindo-se com os sítios e reminiscências históricas da comunidade, sustentando a interligação para compor o Relatório Antropológico da Comunidade Quilombola Aldeia Velha.

O relatório foi elaborado no âmbito do Contrato $N^{\circ} 20.000 / 2016$ entre Instituto Nacional de Colonização e Reforma Agrária (INCRA-MA) e a empresa 3R Tecnologia Ambiental EIRELI - ME, referente à elaboração dos Relatórios Antropológicos de Comunidades Quilombolas do Estado do Maranhão, e contou com a composição de um corpo técnico interdisciplinar: antropólogos, geógrafos, agrônomos e outros da assistência humana. O relatório seguiu as orientações previstas na Instrução Normativa $N^{\circ}$ 57/2009 (INCRA, 2009).

Tem-se como base a investigação antropológica do contexto histórico da formação da comunidade em questão, que tem como fonte, dentre outros, a memória coletiva da: organização social, das manifestações culturais desenvolvidas pela comunidade e sua ligação estreita com a ancestralidade; da vida produtiva; e da concepção ambiental e sua ligação com o sistema cosmológico da comunidade. Especificamente consultamos as referências de Acevedo, Castro, (1998); Arruti (2008, 2009); Almeida (1989, 1997, 2008, 2011), O’Dwoyer (2002), Acselrad (2010); Poutgnat Streiff-Fernat (2011); ao que se refere a história do Maranhão recorreu-se a Mário Meirelles (2008), Imesc (2014); memória e identidade Maurice Halbwachs (2006), Eliane Rapchan (2001), Eliane O'dwyer (2007) entre outros. As narrativas e os documentos coletados em campo, tendeu-se em verificar afirmativas dos movimentos sociais no ensejo dos direitos territoriais; direitos étnicos, e no caso da comunidade quilombola Aldeia Velha, a força das instituições vinculadas como a Comissão Pastoral da Terra (CPT), Pastorais Sociais, ou seja, grupos vinculados à Igreja Católica e a força para o surgimento de novos movimentos e grupos étnicos no Brasil, mais especificamente na Amazônia (ALMEIDA, 2011).

Os materiais e métodos usados para desenvolver o trabalho consistiram no levantamento bibliográfico de conceitos que pudessem contribuir para a caracterização da trajetória histórica da comunidade estudada e suas relações territoriais, assim como de documentos e publicações sobre a região. A pesquisa etnográfica foi realizada, por meio do trabalho de campo na comunidade e seu entorno, a fim de caracterizá-la, conhecer seu contexto histórico e as formas de organização social.

O resultado da pesquisa criou condições para a Comunidade Quilombola Aldeia Velha ter sua ancestralidade comprovada, viabilizando a aprovação da primeira peça, essencial para a continuidade dos dispositivos de demarcação da terra e consequentemente, de acordo com a fala da comunidade, a sua libertação.

Pelo caráter político e territorial, o povoado Bica se configura em um campo privilegiado para as observações e análises sobre etnicidade, recomposição territorial, terra, trabalho, institucionalização e luta política, pois suas características tendem a ser, ao mesmo tempo, um território tradicional, assim como se configura como um território de ação pública, pois é um dos povoados, que por meio do movimento e do envolvimento com a igreja progressista, tem a sede da Associação como referência e estrategicamente o povoado Bica serve de abrigo e proteção dos proprietários de terras. 
Propomo-nos nesse texto, descrever como o processo se deu com base nos direitos territoriais, de etnicidade, de organização política e concertações históricas para a conquista de efetivação de peças técnicas para a titulação da terra.

\section{DESCRIÇÃO DO POVOADO BICA}

A Comunidade Quilombola de Aldeia Velha está localizada no município de Pirapemas (pertencente à bacia do rio Itapecuru), situado na microrregião do Vale do Itapecuru e na mesorregião do Norte Maranhense, a $180 \mathrm{~km}$ da capital São Luís. O seu acesso é pela via rodoviária MA-332, a partir do município de Matões do Norte e entrecortando o Município de Cantanhede. O município de Pirapemas e o território de Aldeia Velha são cortados pela ferrovia Transnordestina.

Historicamente Pirapemas era um antigo aldeamento de indígenas, mais tarde, com a colonização, formou-se fazendas e sítios onde predominavam culturas agrícolas de arroz, mandioca, algodão e criação de gado. A fixação do primeiro núcleo humano no local, onde é hoje a cidade, só se efetuou muitos anos depois, com a construção da Estrada de Ferro São Luís-Teresina, dando origem, assim, às primeiras edificações de moradores permanentes, elevado à categoria de município, com a denominação de Pirapemas, pela Lei Estadual $\mathrm{N}^{\circ}$ 821, de 11 de dezembro de 1952, sendo desmembrado de Coroatá. (IBGE, 2017).

A maioria dos povoados estão situados às margens da Estrada de Ferro São LuísTeresina (Transnordestina), iniciada por volta do ano de 1927, para a construção do trecho Itapecuru-Coroatá, onde foram contratados muitos trabalhadores para montagens dos trilhos. Esses trabalhadores se alojavam nas imediações da atual cidade, construindo barracos de palha para abrigar suas famílias e denominaram o pequeno povoado de Esplanada. Com o avanço da obra da Estrada de Ferro, foi aumentando também sua população. A Estação Ferroviária foi a principal responsável pelo desenvolvimento político, econômico e social da Vila Pirapemas, possibilitando o deslocamento das pessoas para outros centros, bem como o transporte de mercadorias.

A implantação da Estação Ferroviária na Vila de Pirapemas foi inaugurada em 1920, e assim como aconteceu na ferrovia de ferro, a construção da estação também atraiu muitas pessoas que vieram dos mais variados lugares como: Caxias, Codó, Coroatá, ItapecuruMirim, Teresina, Fortaleza, João Pessoa, entre outros, que com seus familiares fixaram residência e concorreram para o crescimento da Vila de Pirapemas; sendo posteriormente emancipada, transformando-se em Município de Pirapemas, através da Lei No 821 de 11 de dezembro de 1952, sancionada pelo então governador do Estado Dr. Eugênio Barros. A ponte de ferro da ferrovia Transnordestina atravessa vários povoados, entre eles o povoado Pontes, palco de muitos conflitos territoriais. 
Imagem 1- Estação de Pirapemas. Inaugurada em 1920

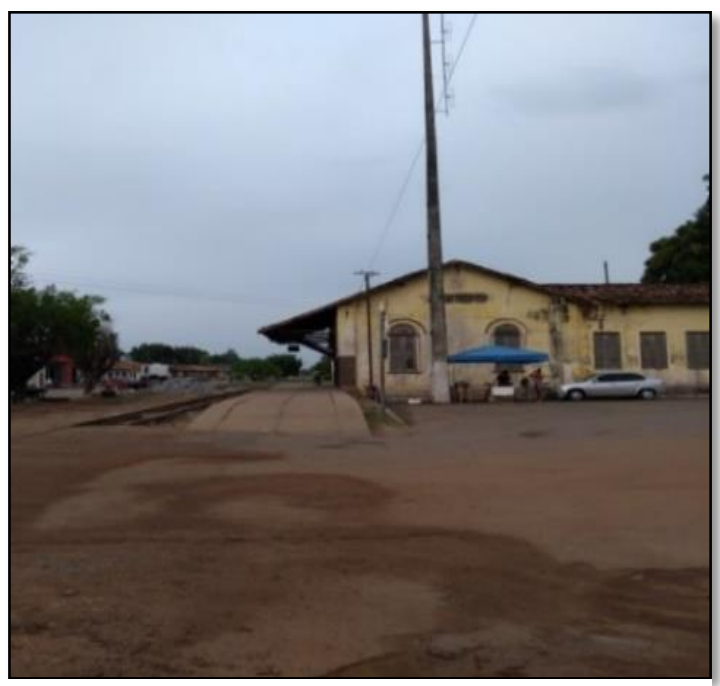

Fonte: Tânia Miranda. (2017)
Imagem 2- Ponte de ferro da Ferrovia Transnordestina. Povoado Ponte.

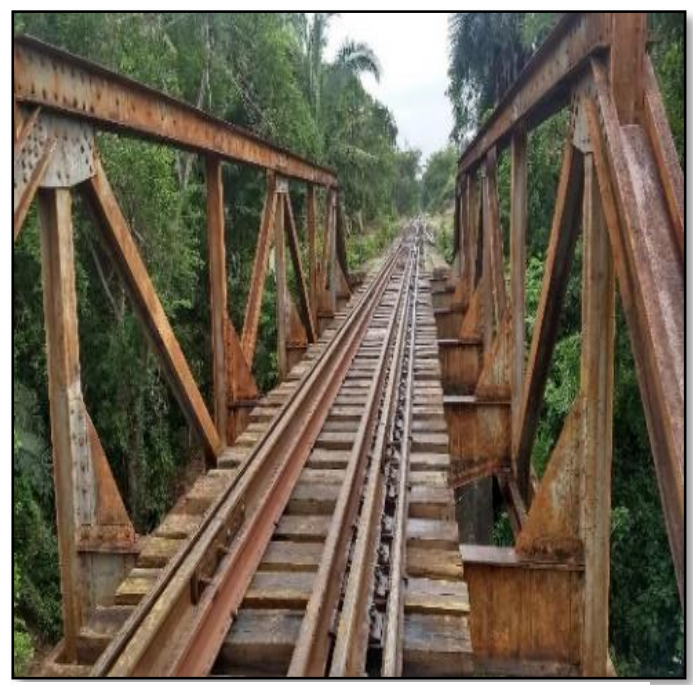

Fonte: Maicon Farias. (2017).

O acesso às comunidades é feito por via rodoviária, em estradas de chão, com alguns trechos construídos pela própria comunidade para o acesso mais rápido.

A distância média do território para a área central do município de Pirapemas é de aproximadamente $22 \mathrm{~km}$, utilizando transporte motorizado, carro ou motocicleta, mas a maioria dos moradores utilizam-se de bicicletas e os ônibus da linha municipal, que saem em dias e horas marcadas para os outros municípios.

O povoado Bica pertence ao corpo de povoados do Território Quilombola Aldeia Velha. O território foi reconhecido como remanescente de quilombos pela Fundação Cultural Palmares (FCP) no dia 19 de dezembro de 2011. Este território é composto por onze (11) comunidades $^{2}$, sendo elas: Pontes, Salgado, Santo Honório, Leão, Bica, Panamirim, Vista Alegre, Afoga Bode, Centrinho, Panaca e São Benedito dos Pretos, totalizando 242 famílias, sendo Pontes com 35 famílias, São Benedito dos Pretos e Panaca com 31 famílias cada, as comunidades mais populosas da região. O povoado Salgado localizado territorialmente no centro do território quilombola é palco de muitos conflitos com os proprietários ao redor. Já o povoado Bica, tem a centralidade das discussões e decisões da Associação. A comunidade Pontes é a comunidade mais próxima da sede de Pirapemas, ficando a cerca de $3 \mathrm{~km}$ de proximidade. A comunidade mais distante é a São Benedito dos Pretos, a $20 \mathrm{~km}$ da cidade.

O povoado Bica é um local estratégico do território quilombola, pois trata-se de um território eclesiástico ${ }^{3}$ e, é por esse motivo que a sede da Associação Quilombola Aldeia Velha funciona nesse povoado pois o local tem diversas funcionalidades, como os encontros dos associados por meio da capela da comunidade, onde realizam-se as missas, reuniões e oficinas, bem como os eventos para todos os povoados/comunidades.

\footnotetext{
${ }^{2}$ A categoria comunidade é usualmente utilizada pelos moradores da Aldeia Velha. É uma categoria sociológica usada largamente pelo Movimento de Educação de Base (MEB) coordenado pela Igreja Católica na década de 1960. Para a Igreja Católica 'comunidade', em particular, as Comunidades Eclesiais de Base (CEBs) se constituem em um núcleo social onde as pessoas devem ter objetivos comuns. O trabalho da Comissão Pastoral da Terra (CPT) na Aldeia Velha é ainda presente como apoio às comunidades desse território.

${ }^{3}$ Refere-se à gestão eclesiástica vivenciada pela Igreja Católica, faz-se diferenciada da lógica dividida pelo estado - nação, IBGE ou região academicamente reconhecida. Por meio de decisões eclesiásticas, em particular no Brasil, a Conferência Nacional dos Bispos do Brasil (CNBB) se configura em divisões denominadas de regionais, paroquiais.
} 
O povoado Bica é para os demais povoados, abrigo, amparo e proteção. Residem na comunidade 11 famílias. As fotos indicam os vários tipos de uso da igreja, como o de reforço escolar, reuniões e oficinas realizadas na associação.

Realizamos na sede da associação com representação dos povoados, a oficina de elaboração do croqui do povoado Aldeia Velha, atividade de um dia com conversas, memórias, entre outras atividades. No mapa logístico abaixo, apresentamos o percurso realizado para chegar à comunidade Bica.

Figura 1- Mapa logístico para chegar na comunidade Bica
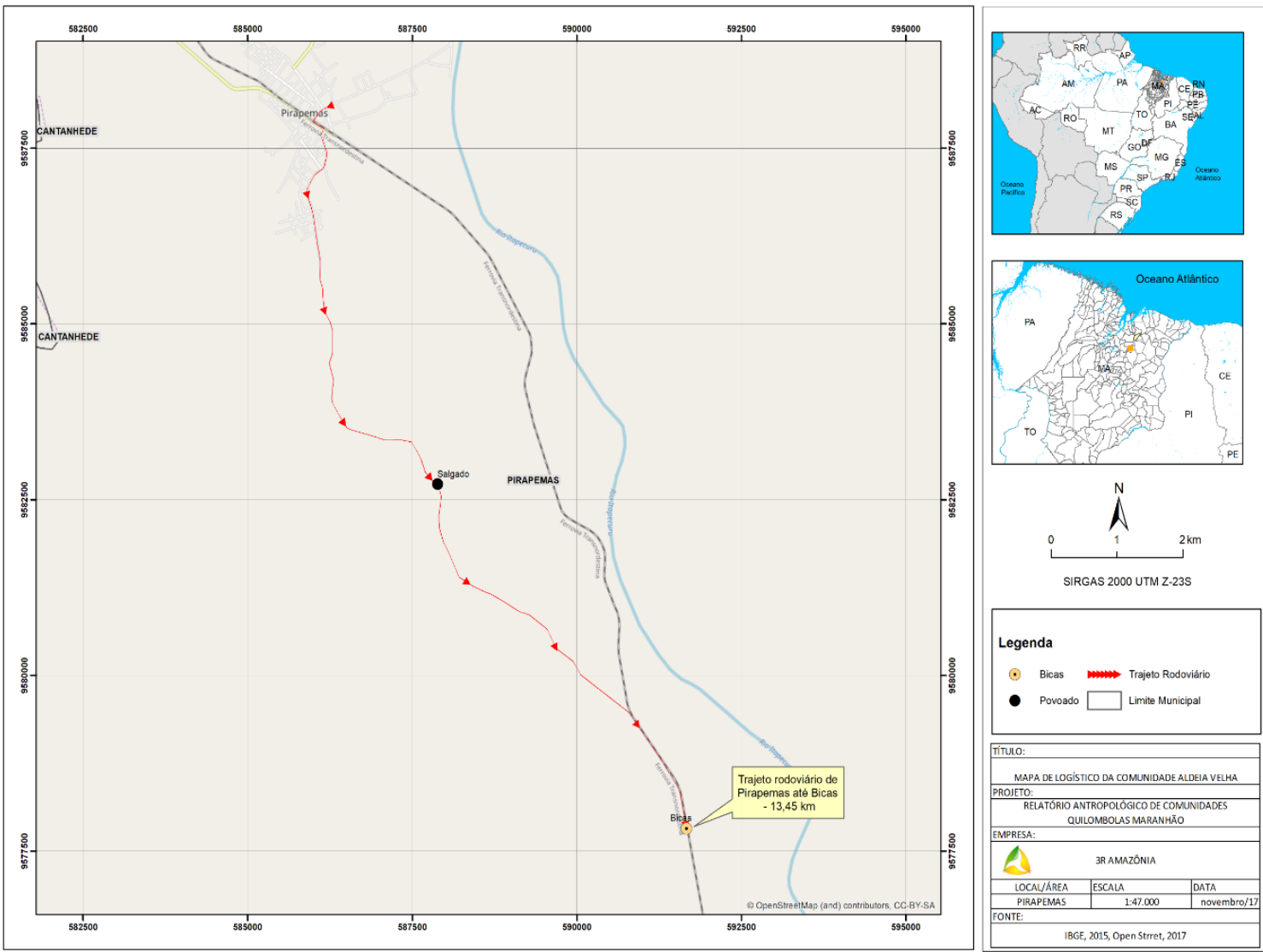

Fonte: 3R, dez. 2017.

A seguir imagens da Igreja e Sede da Associação Quilombola de Aldeia Velha, comunidade Bica. No período da festividade de São Lázaro padroeiro do povoado Aldeia Velha, as celebrações se realizam ao redor da igreja. 
Imagem 3- Igreja

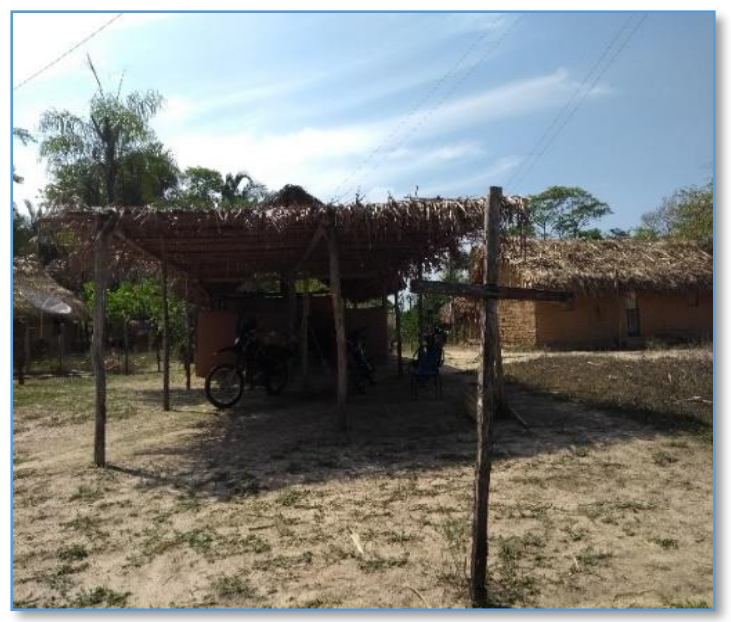

Fonte: Maicon Farias. (2017)
Imagem 4- Reforço escolar

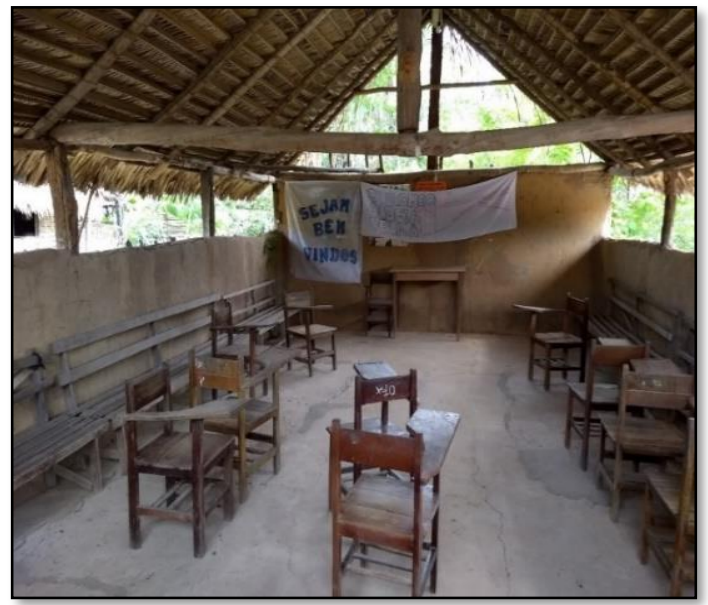

Fonte: Tânia Miranda. (2017)

Imagem 5- Reunião de apresentação da equipe 3R na comunidade Bica

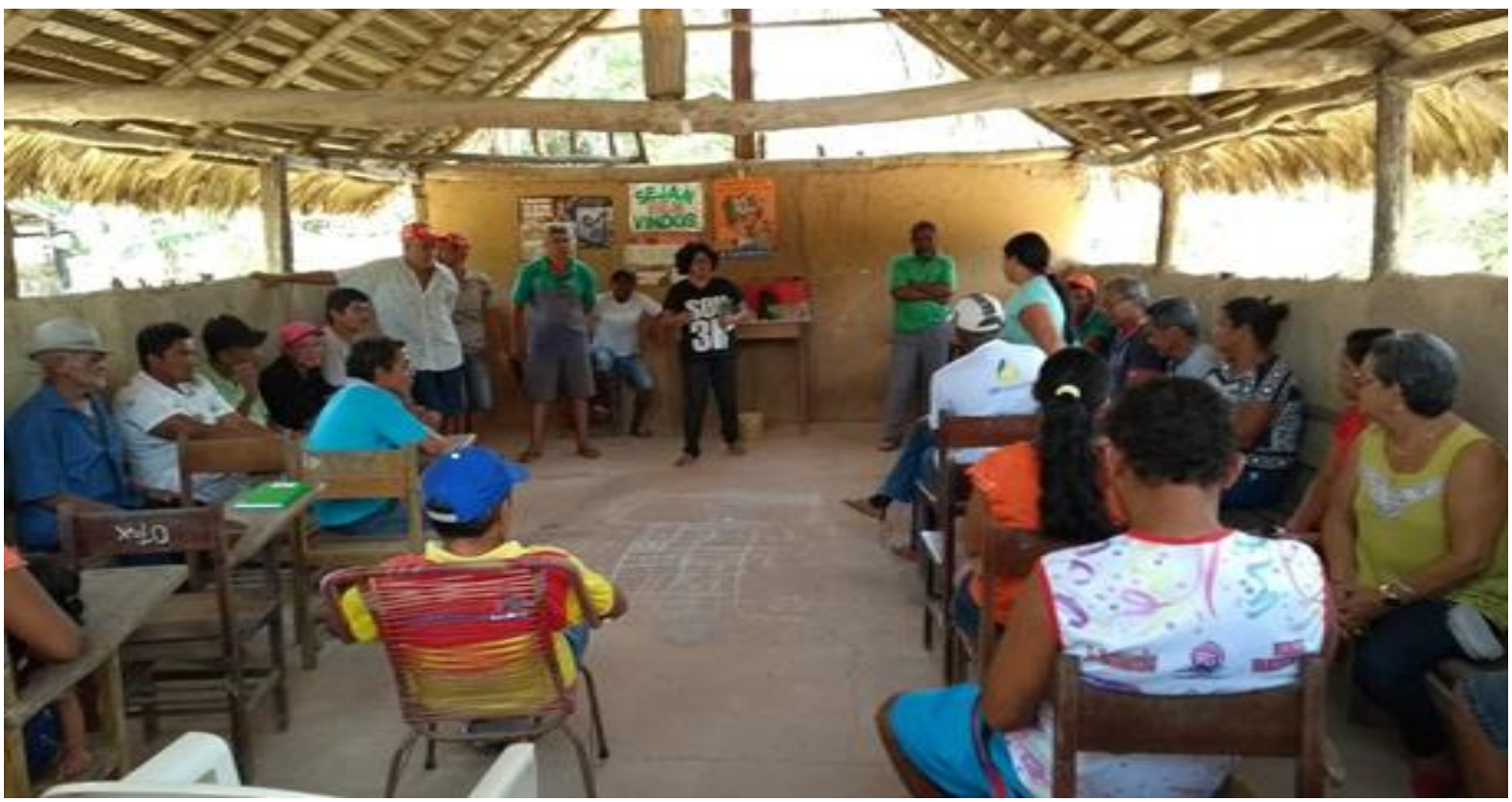

Fonte: Eldenilson Monteiro, 19 out. 2017

Abre-se aqui um parêntese para as duas categorias sociológicas: 'comunidade' e 'povoado'. Comunidade, é como eles se definem por sua construção política de valores associados ao uso da terra como comunas tradicionais, fazendo uso dos meios de produção socializados, assim como as resoluções dos problemas locais debatidos, assumidos e resolvidos coletivamente. Povoado, é como administrativamente, são tratados para a aplicação de políticas públicas e, por razões históricas colonizadoras, no sentido de passagens 'crescentes' ou evolutiva: de vila, aldeia, povoado para o pequeno número de pessoas residentes em determinados locais, para se chegar ao tratamento de cidade, de urbano com aspectos particulares da industrialização e sucessivamente da modernização, no que tange o território reivindicado compreendidos "de sentimento de pertencimento local, sentimento que funciona como fator de identificação, defesa e força” (ALMEIDA, 1989, p. 163). 
Imagem 6- Oficina - Construindo o croqui do povoado

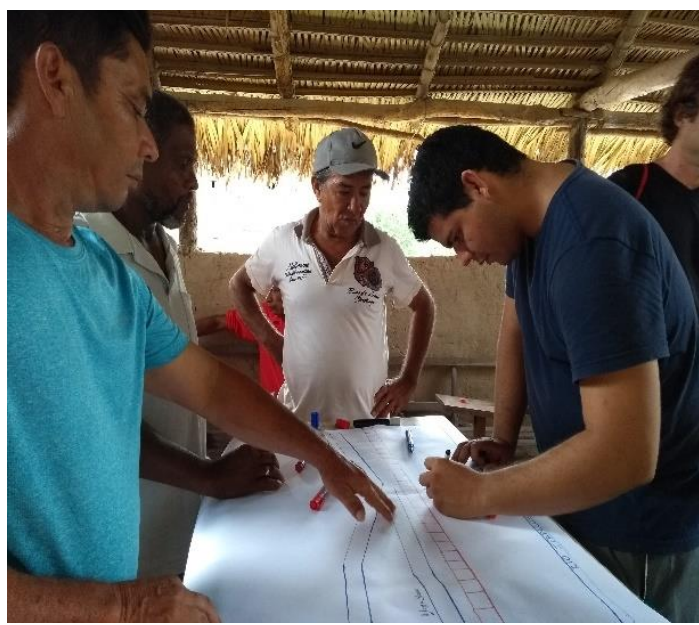

Fonte: Tania Miranda. ( 2017)
Imagem 7- Croqui pronto

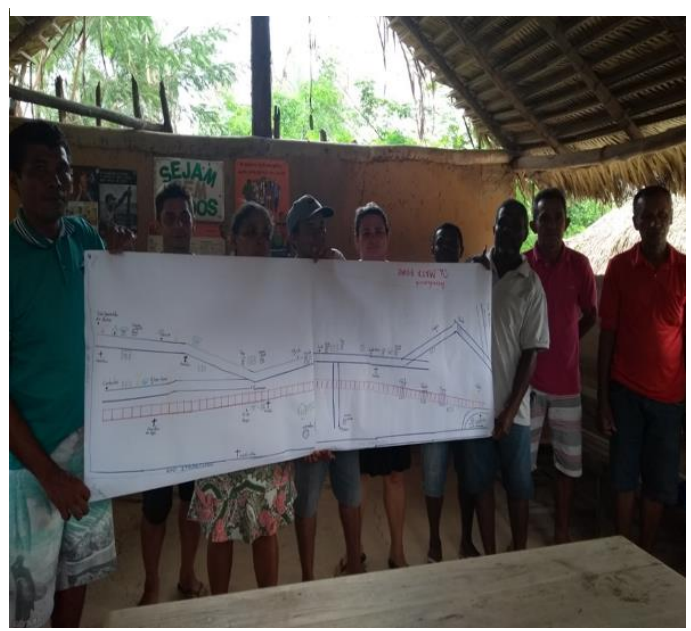

Fonte: Tania Miranda. ( 2017)

O povoado Bica não apresenta sistema de abastecimento público de água. A utilização da água vem de uma nascente que os comunitários chamam de bica, há moradores que possuem condições financeiras e fazem pequenos açudes, armazenando água durante o período das chuvas, entretanto no verão, todos precisam utilizar a água da nascente.

O campo de futebol é o principal ponto de lazer para crianças e jovens, com jogos de futebol para homens e mulheres. Em relação às moradias dos comunitários, elas são de taipa, com paredes erguidas sobre uma armação de vara de bambu ou talos de palmeiras, cobertas com palha e amarradas com cipós.

Ao que se refere à educação escolar, na comunidade há uma escola funcionando em regime de convênio com a prefeitura de Pirapemas, possuindo 34 alunos matriculados em 2017 nas séries do $1^{\mathrm{a}}$ ao $5^{\circ}$ ano. Para continuar os estudos, os alunos precisam se deslocar para cidade vizinha, que fica a aproximadamente $20 \mathrm{~km}$ de distância do povoado.

Não há saneamento básico, nem coleta de lixo por parte da prefeitura, por isso, a comunidade utiliza buracos, feitos após a retirada do barro para construção de casas, para queima do lixo no barreiro ${ }^{4}$. Quando o local fica em desuso, o morador usa esse buraco para plantio de frutíferas, quase sempre de bananeiras, visto que no local ficam depositados insumos orgânicos decompostos e o barreiro (terra que fica no local) está com uma boa qualidade produtiva. $\mathrm{O}$ barreiro é uma prática tradicional realizada em comunidades rurais, em especial da Amazônia, uma vez que a falta de infraestrutura e de saneamento básico é comum em todos os povoados. Já a energia elétrica é fornecida pela cidade de Pirapemas.

\section{PROCESSOS DE EXPROPRIAÇÃO DAS TERRAS QUILOMBOLAS EM PIRAPEMAS}

O que percebemos na reconstituição histórica da família Corrêa Baima, é que os exescravos, tornam-se donos das terras por doação, passando a administrar a propriedade dessa família, dividindo-se pelas terras e organizando suas vidas. Mas a partir da construção da Transnordestina e a chegada de trabalhadores para a construção da estrada de ferro, o território começa a ser ocupado e casas começam a surgir dando origem a outros

4 Palavra êmica para um tipo de buraco feito no chão, onde são depositados entulhos, folhas secas e lixo doméstico para a decomposição do lixo e queima. 
povoamentos no território. Esse período dá início ao processo de expropriação das terras dos Corrêa Baima, da família de Ana Preta (Ana Nília). Por estes não terem conhecimento suficiente para tratar com documentação e impostos, foram "enganados" por um dos que chegaram para trabalhar com retirada de madeira para fazer dormente para os trilhos do trem, Antônio Teixeira Ribeiro.

Quem retrata os acontecimentos é seu Manuel Pereira da Silva, conhecido como Venerando, que trabalhou por muitos anos para um dos donos dessas terras, como empregado e capataz de uma das fazendas que se criou nos territórios.

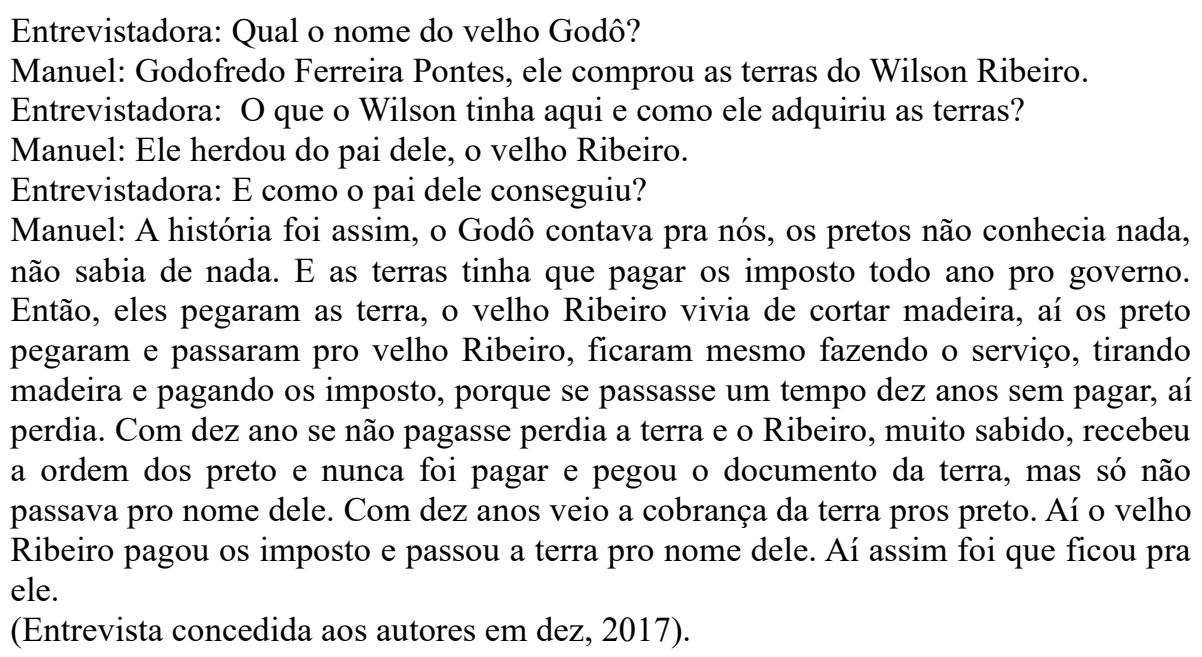

A narrativa enfatiza que Antônio Teixeira Ribeiro enganou os negros Baima, usurpando seus documentos e se apossando das terras. É notado que um de seus herdeiros, o Wilson Ribeiro, que foi o primeiro prefeito de Pirapemas, começou a repartir as terras. Esses moradores, segundo Venerando, trabalhavam a terra "em comum". Essa expressão justifica a forma tradicional de uso da terra nas comunidades negras rurais do Brasil, em que se refere ao imbricamento das atividades agrícolas (roça de mandioca) e criatórias (criação de porcos, galinha, boi, pato, bode, etc.) como formas de manejo adequadas à lógica coletiva de vida em comunidade, desde o manejo da lavoura, de recursos da floresta como a coleta de coco babaçu e a produção de seus derivados, as pescarias e a retirada de madeira para usos domésticos, pautados na reciprocidade e coadjuvando-se.

A partir de 1950, o estado do Piauí passou por um período de seca e Pirapemas absorveu muitos moradores, entre eles, o piauiense Pedro Petra que comprou terras e sítios em Aldeia Velha. Aos poucos o processo de expulsão foi se acirrando e os moradores originários dessa terra foram saindo devido à opressão, à obrigação de pagamento de foro e à proibição das brincadeiras de tambor de crioula e do toque da macumba. Mas um dos principais compradores foi Godofredo Ferreira Pontes, o Velho Godô, que veio do Piauí, segundo Venerando, foi ele que "colocou ordem" na região, instituindo nas terras o sistema de pagamento de foro ${ }^{5}$ para os trabalhadores que quisessem ficar.

Algumas famílias ainda continuam sua trajetória do território, outras são expulsas ou se retiram, indo viver na cidade de Pirapemas e outras localidades. Em todas as comunidades há processos de apropriação, consolidado a partir dos anos 1950, cuja principal forma se dá

5 É uma espécie de imposto pago pelos quilombolas aos fazendeiros, tanto em espécie como em forma de produção, para poder viver nas terras e plantar. É comum os proprietários de terra, grandes ou pequenos, em alguns lugares no Maranhão adotarem o sistema de "aforamento", mantendo assim as famílias de ex-escravos e seus descendentes diretos, pelo poder de coerção, a cobrança de foro. Em Aldeia Velha este sistema incide em uma boa parcela das famílias. A pesquisa encontrou em todas as comunidades, tal incidência a peso de muitos conflitos, ameaças e até mortes entre os quilombolas e proprietários. 
pela grilagem e o aforamento, como uma dinâmica de mando do lugar, diante dos trabalhadores descendentes dos escravos e donos das terras doadas, assim como dos trabalhadores que chegam a partir da construção da estrada de ferro.

As famílias que permanecem no território fazem roças e quebram coco, criam animais de pequeno porte e permanecem nos povoados diante de conflitos das terras repartidas, que engloba as 11 comunidades que foram constituídas no território, cujos moradores, ao longo do tempo, principalmente depois da década de 1950, enfrentam vários conflitos com cerca de 32 grileiros nestas terras, em que há três famílias com maior concentração de terra no território: a família Pontes, a família Godô e a família de Roberto, conhecido como Roberto do Peru.

O filho do velho Godô, Antônio Godô, vendeu sua parte das terras a outros fazendeiros, iniciando uma grande situação de expropriação entre os anos 60 e os anos 90, quando centenas de famílias foram expulsas do local. Na década de 1970, surge uma nova fase de conflitos, após a venda de terras para outros fazendeiros.

\section{ABORDAGEM CONCEITUAL E TEÓRICA}

O território quilombola de Aldeia Velha é resultado da organização de 11 comunidades que reivindicam a ancestralidade das terras da família Corrêa Baima, terras que remontam ao período colonial brasileiro, e que foram doadas por Viriato Corrêa aos negros que também herdaram o sobrenome Corrêa Baima. As 11 comunidades, hoje organizadas na Associação do Território Quilombola Aldeia Velha, nasceram de um período de profunda exploração de sua força de trabalho, de expulsão de muitos, restrições de uso da terra para sua reprodução social e cultural, e da luta contra o aforamento. Em meio aos muitos conflitos pela terra, travaram suas lutas na reconstituição da descendência e da tradicionalidade negra, baseando-se na memória social e a etnicidade do grupo.

A memória dos quilombolas remonta à tradição de ocupação histórica das terras, dos lugares, caminhos antigos, das atividades extrativistas e agrícolas, desde o período colonial, numa terra doada aos negros que ali viviam num passado de escravidão. Os quilombolas de Aldeia Velha, a partir da perda do domínio de suas terras, da relação com outros tantos retirantes, vindos para a região com a construção da estrada de ferro, também subjugados ao processo de exploração local pelo pagamento de foro, vão reconfigurando a vida neste território.

A reafirmação étnica, os quais se configuram por consensualidade e legitimação territorial, é, para além da referida conquista normativa, pois é no território que a etnicidade dos grupos se perpetua, estes compartilham valores culturais fundamentais, colocados em prática num contexto de ação, se compõe em um campo de comunicação e interação; se identificam e são identificados por outros e se constituem em uma categoria que se distingue das demais categorias da mesma ordem. (POUTGNAT; STREIFF-FERNAT, 2011).

É importante frisar que a emergência das demandas pela demarcação dos territórios quilombolas, se dá em face às disputas por terra no meio rural brasileiro. Os então "camponeses", "posseiros" e outras categorias utilizadas para designar comunidades negras rurais, assumem a luta pelo reconhecimento de seus territórios para se defenderem do avanço de seus diversos antagonistas (grileiros, grandes latifundiários, ou mesmo grupos articulados para a instalação de grandes empreendimentos) sobre seus territórios.

O conceito de "etnia é formulado a partir de conflitos sociais" (ALMEIDA, 1998, p.52). Sobre a noção de etnicidade, Arruti (1997, p. 25) acrescenta,

[...] a relevância do movimento analítico que aproxima as "comunidades remanescentes de quilombos" está na problematização do seu processo de autoconstituição como grupos sociais e culturais diferenciados, ou em outros termos, no que a literatura antropológica convencionou chamar de etnogênese. 
Ainda segundo este mesmo autor "o uso da categoria etnicidade é sua remissão ao movimento de um determinado agregado no sentido da constituição de uma unidade política". (ARRUTI, 1997, p. 26). A etnicidade não marcaria, portanto, o reconhecimento de semelhanças previamente dadas, inscritas naturalmente nos corpos e nos costumes e cuja explicação estaria no passado, mas uma atitude positiva e propositiva, através da qual seriam produzidas demandas e um projeto comum, ou seja, cuja vinculação e razão de ser estão nos processos instituídos e instituintes. Os trabalhos sobre etnogênese inscritos em rearranjos classificatórios de "raça", "etnia" e avançando para "classe" que a opção por etnia corresponde a uma postura política, pois os estudos de grupos emergentes sinalizaram que "as fronteiras podem ser criadas ou mudar de natureza quando entra em cena a disputa por recursos, em especial os recursos fundiários" (ARRUTI, IDEM, IBDEM).

O refúgio de muitos dos escravos africanos, de escravos fugitivos e de remanescentes de quilombos se organizaram de maneira etnicamente fechada e socialmente autônoma, praticando agricultura de subsistência, coletando espécies de vegetais, caçando para consumo próprio e para a comercialização no mercado de possível alcance destas comunidades. $\mathrm{O}$ refúgio, o isolamento e sucessivamente a autonomia foi a maneira encontrada, por muitos, para a sobrevivência de suas raízes, crenças e manifestações culturais, assim como sua cosmovisão vinculada à ancestralidade.

A cosmovisão de um grupo, amparado em sua ancestralidade, é fruto da oralidade e das práticas de estratégias de manutenção e afirmação da identidade; estas se materializam em um contexto de organização social, cultural, política e territorial dos grupos étnicos que se autodenominaram quilombolas.

Enfatiza-se que a identidade de um grupo não parte apenas da vivência em si, mas da construção do ser simbológico, do reconhecimento de pertença (pertencimento) ao grupo e, sucessivamente, de ser reconhecido no contexto grupal. E, mesmo que este reconhecimento tenha acontecido pelo amadurecimento, incentivado em determinado tempo histórico, foi um elemento substancial e necessário para as alterações conceituais, no qual os grupos estiveram diretamente relacionados ao processo entendido de ressemantização indicada por Arruti (2008), que enfatiza que o sentimento de pertença não depende da cor da pele ou da origem africana. Neste processo, entendido como étnico, a identidade está intrinsecamente vinculada à ideia de pertencimento local, ou seja, é o local que se percebe, que entra em ação, que ressignifica, que traduz a vida ao processo de ocupação tradicional das terras. A terra, como enfatiza Almeida, (2008) "é de uso comum; e funciona como fator de identificação, defesa e força”.

Neste sentido, territórios de usos comuns tornam-se para este autor, categoria central não só analítica, mas política, pois

[...] as formas de uso comum designam situações nas quais o controle dos recursos básicos não é exercido livre e individualmente por um determinado grupo doméstico de pequenos produtores diretos ou por um dos seus membros. Tal controle se dá através de normas específicas instituídas para além do código legal vigente e acatadas, de maneira consensual, (pelos) vários grupos familiares, que compõem uma unidade social. São os laços solidários e de ajuda mútua (que) informam um conjunto de regras firmadas sobre uma base física considerada comum, essencial e inalienável. (ALMEIDA, 2008, p. 28 - 29).

A construção dos laços solidários é empreendida por grupos étnicos na condição de enfrentamento às condições desumanas em que estão submetidos. A etnicidade tem sido refletida como um fator primordial para mobilização política "pois ela permite combinar interesses e vínculos afetivos". (POUTGNAT STREIFF-FERNAT, 2011, p. 98). Seu sucesso, deve-se ao fato de ela mobilizar símbolos culturais identificáveis, tais como a dança, o modo de cultuar os bens concretos e abstratos. 
Com base nas questões de afirmação política, acesso à terra, uso comum da terra, acesso a políticas públicas e a titulação coletiva da terra, a comunidade quilombola da Aldeia Velha, em conjunto com instituições políticas, sociais, religiosas, como a Comissão Pastoral da Terra (CPT), em concomitância à participação ativa nas Comunidades Eclesiais de Base $(\text { Ceb's })^{6}$ trava a luta pelo território. Os dois grupos, ligados à Igreja Católica, são motivadores para os quilombolas, na medida em que promovem a reflexão sobre a realidade e como fator sucessivo para as ações concretas de mudança. Trabalhadores rurais foram incentivados a criar uma organização social legalizada, tipo associação, com fins de manter a relação da comunidade com instituições políticas locais.

Assim, em 2014 foi criada a representação política da entidade, Associação do Território Quilombola Aldeia Velha, fruto de reivindicações pela permanência em suas terras e a busca de projetos de desenvolvimento para a comunidade. Foram intensas lutas desses grupos em conjunto com organizações de cunho legislativo e de trabalhos acadêmicos que até hoje interagem na consolidação de um campo político organizativo ao redor desses territórios. Acselrad (2010) em sua análise sobre demanda territorial acrescenta,

[...] uma demanda por território, ao contrário [de uma simples demanda por terra] evoca questões de poder, de identidade, de autogestão e de controle dos recursos naturais. Uma demanda territorial busca impor uma nova territorialização que, no interior do espaço nacional é fundamentada na cidadania territorial, tenta redefinir a relação dos grupos com o Estado e a nação. (IDEM, 2010, p.14).

A emergência da organização das comunidades quilombolas tem suas raízes na concepção dos trabalhadores da área rural e/ou do campo, que criam lutas específicas e contribuem para o estabelecimento e promulgação de leis também específicas. A criação da Coordenação Nacional das Comunidades Negras Rurais Quilombolas (CONAQ) em 1996, é um dos marcos de contribuição, enquanto movimento político organizado que afirma a identidade étnica inserida no conjunto das lutas dos quilombolas pela posse de suas terras centenárias. Esta instituição tem claro o seu objetivo,

[...] lutar pela garantia de propriedade de terra, pela implantação de projetos de desenvolvimento sustentável e pela implementação de políticas públicas levando em consideração a organização pré-existente das comunidades de quilombo, em vários estados brasileiros, tais como uso comum da terra e dos recursos naturais, em harmonia com meio ambiente, que são referências de vida. (COSTA, 2017, p .6).

Como marco da oficialização do termo "território" referente a essas populações, temse o Decreto $\mathrm{N}^{\mathrm{o}}$ 6.040, de 7 de fevereiro de 2007, que institui a Política Nacional de Desenvolvimento Sustentável dos Povos e Comunidades Tradicionais, onde no Artigo $3^{\circ}$, no Inciso II, reza,

Territórios Tradicionais são espaços necessários à reprodução cultural, social e econômica dos povos e comunidades tradicionais, sejam eles utilizados de forma permanente ou temporária, observado, no que diz respeito aos povos indígenas e quilombolas, respectivamente, o que dispõem os arts, 231 da Constituição e 68 do

6 CEBs são pequenos grupos organizados em torno da paróquia (urbana) ou da capela (rural), por iniciativa de leigos, padres ou bispos. As primeiras surgiram por volta de 1960, em Nísia Floresta, arquidiocese de Natal, segundo alguns pesquisadores, ou em Volta Redonda, segundo outros. De natureza religiosa e caráter pastoral, as CEB's podem ter dez, vinte ou cinquenta membros. Nas paróquias de periferia, as comunidades podem estar distribuídas em pequenos grupos ou formar um único grupão a que se dá o nome de comunidade eclesial de base. É o caso da zona rural, onde cem ou duzentas pessoas se reúnem numa capela aos domingos para celebrar o culto (p.7). Artigo "O que é Comunidades Eclesiais de Base" de Frei Beto. Disponível em: http://www.dhnet.org.br/direitos/militantes/freibetto/livro_betto_o_que_e_cebs.pdf/. Acesso em: jan. 2018. 
Ato das Disposições Constitucionais Transitórias e demais regulamentações. (BRASIL, [1988] 2007).

Esse Decreto oficializa uma concepção de território construída pelos atores sociais ao longo de sua história de luta por existência e reconhecimento desta. (LEROY, 2016, p. 15). $\mathrm{Na}$ perspectiva acadêmica, Cara (1994) analisa que o território pode ser carregado de sentidos: Territórios físicos ecossistêmicos em sintonia com os seus habitantes; Territórios ancestrais carregados de memória afetiva e espiritual; Territórios laboratórios de experimentos e de construção de conhecimentos; Territórios de lutas e de elaboração de definições de identidades; Territórios construídos em torno de laços familiares; Territórios em que a individualidade é inseparável do coletivo. Neste sentido, Almeida (1989, p. 72) sinaliza que os territórios não obedecem a um conceito único, mas a diversidade é enorme para cada um, é a territorialidade específica que vai configurar seu território, "funciona com fator de identificação e defesa". O conceito assim, torna-se categoria central não só analítica, mas política.

\section{POVOADO BICA: PROCESSOS DE ORGANIZAÇÃO POLÍTICA EM BUSCA DA TITULAÇÃO TERRITORIAL}

O povoado Bica nasceu em volta dos muitos conflitos entre o proprietário Antônio Godô (filho do velho Godô), que se intitulava herdeiro das terras de seu pai. Vários foram os conflitos levando a perseguições de lideranças, queima das hortas, destruição de viveiros de criadouros de galinha e porcos, além de muitas ameaças às famílias do povoado Bica.

Os primeiros moradores dessas terras foram obrigados a deixar o local e se instalarem na cidade. Muitos foram em busca de trabalho quando iniciada a construção da estrada de Ferro. Outros foram chegando de outros estados e se alojaram no local. Um dos motivos de afastamento das terras está vinculado à perseguição de novos proprietários que foram se alojando e se apropriando de terras na região. Os depoimentos sinalizam que bastavam chegar e dizer que era dono, apresentava um documento, cercava e iniciava o processo de violência, aí não se podia mais trabalhar na terra. Os que permaneciam nas terras para produzir, tinham que pagar, assim relata:

No tempo do Zequinha, nós demo foi 50 saco de arroz, e ele tava dizendo que nós tinha roubado ele, enganado ele, pois é, nós fizemo a roça aqui na mata dele aqui, roça monstra, até esse cara tava mais nós, nós demo foi 50 saco de arroz, não foi só eu que dei não, mais o pessoal, porque a roça fui eu que aluguei o terreno pra fazer a roça, na hora teve que ajuntar o arroz todinho pra dar pra ele, "safado tu ainda me roubou, me enganou", que diabo enganou rapaz, 50 saco de arroz, e dei sacada, e dei bem aqui na usina. (Antônia Luzia Conceição Barros da Silva, 67 anos, Povoado Bica, dez. 2017).

Ao fluir a história, Joana Alvez e Maria dos Remédios começaram a dizer que teve um tempo que "os pretos deixaram de ser besta, cansou de sofrer, de entregar tudo que produzia o dia todo e entregar na mão dos proprietários". Maria dos Remédios enfatiza que um dia a confusão pela terra começou, "tinha uma família que chegou do Piauí e comprou as terras que a gente nem soube. Uma tal de Nilza e o marido dela, o Satiro e começaram a cobrar o foro".

A partir de 1950, essas comunidades e as suas lideranças sofreram muitas ameaças de mortes, de despejos, de casas de serem queimadas, pois $90 \%$ das casas são de pau a pique cobertas de palha. Mas os maiores conflitos se apresentam na forma de queimadas, com incêndios criminosos, derrubas de palmeiras e madeiras para venda, extração de pedras, grandes desmatamentos para planta de capim, comprometendo os igarapés, brejos, juçarais e buritizais, destruindo as nascentes e comprometendo a vida das comunidades com a falta 
d'água e de alimento. Eles tomam de conta das terras deixando as comunidades sem a terra para trabalhar e impedidos de fazerem suas roças.

A mediação para os conflitos surgiu após muitas assembleias entre os povoados, bispo, padres e religiosas da Igreja Católica, acertaram o pagamento da dívida e a compra do território e a seguir a doação. Esse processo de doação se deu por volta de 1978, a Diocese de Coroatá no bispado de Dom Reinaldo Ernest Heriberto Pünder ${ }^{7}$.

Os acertos se deram entre as 13 famílias do povoado Leão e as 11 famílias do povoado Bica. Juntos somam 24 famílias e estão em 240 hectares. A foto da nascente abaixo, dá nome ao povoado.

Imagem 8- Nascente no povoado Bica

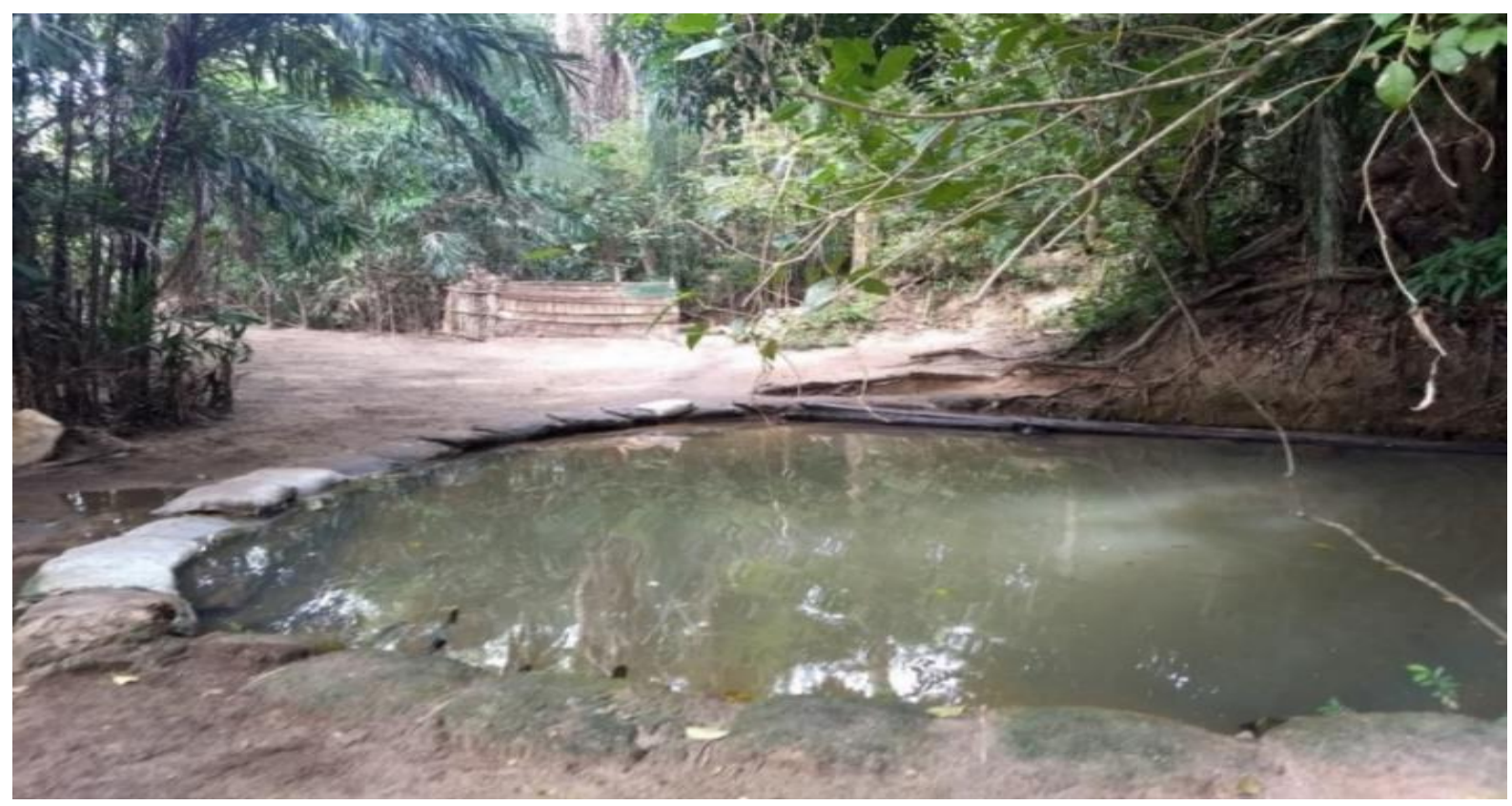

Fonte: Maicon Farias. (2017)

O fato de o território pertencer a Igreja Católica, título doado ao povoado Bica incluindo uma parte do povoado Leão, dá as famílias o sentimento de proteção das invasões de outros fazendeiros, da cobrança do foro e outros efeitos herdados historicamente, e por isto centralizam as discussões e decisões dos povoados em seu território. À época, em 2017, o coordenador executivo da Associação do Território Aldeia Velha, Zé Patrício (47 anos), morador do povoado Pontes, nos fala da importância da tomada de consciência, advinda da atuação da Igreja Católica do município (início com a paróquia, depois com a CPT), frente aos conflitos pela posse da terra, tal disposição os coloca de frente com os demais proprietários que não conseguem apresentar documentos de títulos legais das terras, tendo que usar da violência para garantir o poder e o mando sobre esse território.

O processo de organização da associação aconteceu no povoado Bica, inclusive as reuniões com apoio da Comissão Pastoral da Terra (CPT), foram inúmeras as reuniões realizadas para tratar de uma instância que representasse os interesses das comunidades, resultando na criação da associação. Foi um processo com ampla discussão entre todos os povoados, [...] vários momentos de debates, assessoria dos advogados da CPT. A CPT é o

7 Bispo Alemão que trabalhou na região, ele foi o $1^{\circ}$ bispo diocesano de Coroatá desde 1978. Disponível em: http://www.arquidioceseolindarecife.org/2011/01/morre-o-bispo-de-coroata-ma-dom-reinaldo-punder/. Acesso em: jan. 2018. 
único grupo que dá apoio pra nós. Nós conseguimos os recursos para a legalização com a Igreja e com uma vaquinha que nós mesmos fizemos [...] (Zé Patrício, 47 anos, dez. 2017).

Em grande assembleia com representatividade de todos os povoados e ainda, subsidiados pela Convenção 169 da OIT, que reconhece a autodeterminação dos quilombolas, envolvendo o direito de escolha na organização e desenvolvimento de seus modos de vida, "[...] bem como as terras que ocupam ou utilizam de alguma forma, e de controlar, na medida do possível, o seu próprio desenvolvimento econômico, social e cultural" (BRASIL, [1988] 2017). Além do Instrumento que regulamenta o procedimento para identificação, reconhecimento, delimitação, demarcação, desintrusão, titulação e registro das terras ocupadas por remanescentes das comunidades dos quilombos; acompanhado dos instrumentos previsto no inciso I, e alíneas do artigo 10 da IN57/200, o território Aldeia Velha se autodeclarou quilombola.

A Associação do Território Quilombola Aldeia Velha foi instituída em 17 de setembro de 2014, tem uma peculiaridade em relação à forma de organização associativa mais comum no Brasil, visto que seu funcionamento tem como característica, a descentralização em Conselhos representativos que fazem a ponte (diálogos e inter-relações) entre as comunidades e seus associados. Entre os muitos conflitos das representações das comunidades ao entorno de outras comunidades, nos acertos, 11 povoados são representados pela Associação, que tem como responsabilidade a administração, prezar pelo patrimônio material e imaterial, móvel e imóvel das comunidades, cuja bandeira fundamental de luta é a regularização do território.

São considerados sócios da associação, os remanescentes de quilombo que integram e/ou vierem a integrar as comunidades quilombolas de Aldeia Velha, com os devidos direitos de participação nas assembleias gerais, votar e ser votado, apresentar, solicitar reivindicações de seu interesse ou de interesse da Associação e das comunidades. Ainda segundo os procedimentos estatutários, todos os associados e seus herdeiros têm igual direito sobre as terras de propriedades das comunidades quilombolas do território Aldeia Velha. Os associados têm direito de prática de agricultura, caça, pesca, extrativismo desde que esteja em harmonia com a mãe-natureza. (ESTATUTO DA ASSOCIAÇÃO, 2014).

Para Zé Patrício (2017, 47 anos) a criação e legalização da associação viabilizou processos de reivindicação à Fundação Palmares como a autodefinição de comunidade quilombola, acordo satisfatório para ter a garantia de liberdade e a garantia do modo de vida das comunidades, pois viviam nas terras "alheias" sujeitos ao regime de trabalho superexplorado, viviam no "assujeitamento". A condição de assujeitado implica em controle visto como excessivo. "Viver nas terras alheias é ser assujeitado" (José Bispo,76 anos). Não é a condição de trabalho que indica tal situação e sim a condição de moradia, aliás, a falta dela, que impõe a obrigação de se ter que morar na terra do "patrão", assim como a cobrança de foro, que complementa essa condição de assujeitamento, "depois de tanto trabalho da família 'temos que entregar parte da produção". (José Bispo, 76 anos).

A Associação das comunidades quilombolas realiza suas reuniões de rotina, assembleias ordinárias e extraordinárias em sua sede, igreja, escola localizado no povoado Bica. Por meio da associação reivindica-se muitas demandas quanto aos serviços públicos, a comunidade não conta com a coleta de lixo, nem com serviços de esgoto ou água encanada. A energia elétrica chega via extensão da rede do município, fruto da iniciativa da associação. A coordenação da associação, ainda reivindica outra parte das terras no povoado Leão, que vivem em conflito com os proprietários antigos como Antônio Godô, Zequinha Ortegal e atuais como Carlos Noventa e Nove. Os moradores do povoado Leão é impedido de entrar nas áreas para trabalhar, havendo ainda desmatamento e derrubada de palmeiras onde as famílias que trabalham ainda precisam entregar ao "proprietário" uma parte da sua produção pelo direito de trabalhar na área.

O povoado Bica tem sido desde o recebimento do título do território, atuante e protagonista nas ações políticas de reivindicações ao Povoado Aldeia Velha; quando os 
coordenadores da associação quilombolas são ameaçados e perseguidos receberam abrigo e proteção neste povoado.

\section{CONSIDERAÇÕES FINAIS}

Neste trabalho nos propusemos a enfocar a história de lutas vivenciadas pelos quilombolas de Aldeia Velha e mostrar o povoado Bica como protagonista nas ações de mobilização e organização pela titulação definitiva das terras, compondo 11 povoados e, com a proposta de área delimitada foi de 7.618,303 hectares, com perímetro de 41.798,549 metros. Lembrando que este território já tem em suas posses 240 hectares de terras doadas pela Diocese de Coroatá para duas comunidades, Bica e Leão.

Até onde podemos acompanhar, vimos o povoado Bica em comunhão com entidades que historicamente lutaram contra ao doloroso processo de escravização de negros africanos, de camponeses e povos originários que se encontram em situação de assujeitamento.

Em termos de representação, o povoado Aldeia Velha atua e em alguns eventos, coordena as lutas atuais e se faz presente nos principais fóruns, conselhos de debates e decisões referentes a luta pela terra e reforma agrária.

Percebeu-se, a coesão do grupo, construída em uma história comum, significando o sentido de permanecer na caminhada, como os próprios quilombolas, costumam falar. A história de ocupação é indissociável do uso comum do território, por um lado para subsistência física, mesmo ligado à economia familiar, por outro lado, as marcas do passado estão espalhadas pelo território, na memória de luta e de resistência, desde o passado mais distante aos períodos atuais.

A que se considerar que este território é marcado ao longo de sua história por processos de expropriação e violência constantes, e que esses processos ainda estão em continuidade em pleno século XXI, chegando a níveis extremos de violação de direitos humanos. Muito recente, agora em 2021, as lideranças locais são ameaçadas de morte, tendo que recorrer a medidas protetivas do Estado, (lideranças que passaram dias e dias escondidos nos matagais de Aldeia Velha ou fugiram pelo rio Itapecuru), há casos de expulsões de núcleos familiares, mesmo em plena pandemia, há destruição de casas e de áreas de roças dos quilombolas e, inclusive com proibições de manifestação cultural religiosa, dentre outros.

O relatório, após a aprovação, recomendou ao INCRA-MA dentro de suas atribuições, concluir com agilidade o processo de RTID da Comunidade Quilombola Aldeia Velha, a fim de garantir o título definitivo do território, garantindo constitucionalmente às comunidades quilombolas a apropriação definitiva de seu território e as condições para sua sustentabilidade e a manutenção do modo de vida de seus habitantes. No entanto, o processo continua estagnado.

Os Quilombos certificados e titulados refletem a morosidade e omissão sistêmica que protela e impede o reconhecimento e titulação dos quilombos, em descumprimento à Convenção 169, OIT. Ao povoado Aldeia Velha, ainda há muito para resistir e lutar.

\section{REFERÊNCIAS}

ACSELRAD Henri. Ambientalização das lutas sociais - o caso do movimento por justiça ambiental. In: Estudos Avançados, Dossiê Teorias Socioambientais, vol.24 no.68 São Paulo, 2010. Disponível em: http://dx.doi.org/10.1590/S0103-40142010000100010. Acesso em: dez. 2020

ACEVEDO, R.; CASTRO, E. Negros dos Trombetas: Guardiães de Matas e Rios. Belém: editora CEJUP, 1998. 
ALMEIDA, Alfredo Wagner B. de. Quilombos: Repertório Bibliográfico de uma Questão Redefinida (1995-1997). BIB, Rio de Janeiro, n. 45, $1^{\circ}$ semestre de 1998, p. 51-70.

ALMEIDA, Alfredo Wagner B. de. Terras de preto, terras de santo, terras de índio - uso comum e conflito. In: CASTRO, Edna; HÉBETTE Jean. (org.,). Na trilha dos grandes projetos: Modernização e Conflito na Amazônia. Belém PA: NAEA/UFPA, 1989. p.163 196.

ALMEIDA, Alfredo Wagner B. de. Os quilombos e as novas etnias. In: O'DWYER, E. (org.). Quilombos: identidade étnica e territorialidade. Rio de Janeiro: Ed. FGV, 2002. p. 4381 .

ALMEIDA, Alfredo Wagner Berno de. Terra de quilombo, terras indígenas, "babaçuais livres, "castanha do povo", faixinais e fundos de pasto: terras tradicionalmente ocupadas. 2. ${ }^{a}$ Ed, PGSCA- UFAM, Manaus, 2008.

ALMEIDA, Alfredo Wagner Berno de. Terra de quilombo, terras indígenas, "babaçuais livres, "castanha do povo", faixinais e fundos de pasto: terras tradicionalmente ocupadas. 2. ${ }^{a}$ Ed, PGSCA- UFAM, Manaus, 2008.

ALMEIDA, Alfredo Wagner Berno de. Quilombolas e novas etnias. Manaus: UEA Edições, 2011.

ARRUTI, José Mauricio. A emergência dos remanescentes. A emergência dos "remanescentes" notas para o diálogo entre indígenas e quilombolas. Mana 2(3) 7-39 1997. Disponível em: https://doi.org/10.1590/S0104-93131997000200001 Acesso em: 22.fev. 2018, BRASIL. Decreto No 6.040, de 7 de fevereiro de 2007.

CARA, Roberto Bustos. Territorialidade e identidade regional no sul da Província de Buenos Aires. In: SANTOS, Milton; SOUZA, Maria Adélia A.; SILVEIRA, Maria Laura. (org.). Território, Globalização e Fragmentação. São Paulo: Editora HUCITEC-ANPUR, 1994.

COSTA, Ivan Rodrigues. CONAQ: Um Movimento Nacional dos Quilombolas. 2017. Disponível em: http://docplayer.com.br/16946833-Conaq-um-movimento-nacional-dosquilombolas.html. Acesso em: 20 dez. 2017.

O'DWYER, Eliane Cantarino (Org.). "Introdução”, em Quilombos: Identidade étnica e territorialidade. Rio de Janeiro, editora Vozes, 2007.

POUTIGNAT, Philippe;STREIF-FERNAT, Jocelyne. Teorias da etnicidade: seguido de grupos étnicos e suas fronteiras de Fredrik Barth. Tradução: Elcio Fernandes - 2 ed. São Paulo: Ed UNESP, 2011, 250 p. 